\title{
DOES EUROPEAN INTEGRATION MAKE EXPORTS MORE COMPLEX?
}

The authors studied the determinants of export complexity aiming at an assessment of the impact of European integration on increased sophistication of exported goods. It is possible that EU membership leads to higher export complexity due to the emergence of new (advancedtechnology-oriented) comparative advantages and inflow of capital, for instance, in the form of FDI. At the same time, countries without the supply conditions necessary to produce sophisticated products, may specialize in goods that are less complex. Such a theoretical ambiguity leads to the need to empirically assess the importance of EU accession for export complexity.

The study applied panel data analysis. The results indicate that the European Union may have increased the complexity in member states' exports, especially in the less advanced economies.

Keywords: international trade, European integration, European Union, export complexity

JEL Classification: C23, F14, F15

DOI: $10.15611 /$ aoe.2021.1.07

\section{INTRODUCTION}

The patterns of countries' specialization have been scrutinized by economists at least since Adam Smith and David Ricardo. Countries may trade goods according to their comparative advantages, factor endowments and - in the context of intra-industry trade - demand similarities, internal and external scale economies and the life cycles of products. At the same time, since the pioneering studies conducted by Jacob Viner, when regarding the consequence of the establishment of customs unions, economists have claimed that economic integration may significantly affect trade.

One of the features of trade that has become increasingly investigated is export complexity. Hausmann, Hwang and Rodrik (2007) showed that such a sophistication may be an important source of economic growth. Since then the main focus of researchers has been on the development of proper measures

\footnotetext{
* Department of International Trade, University of Lodz, Poland.

** Department of Macroeconomic, University of Lodz, Poland.
} 
of complexity and the discussion about its determinants has been much neglected. This article claims that economic integration may influence what countries produce and trade, hence affecting the aggregate the complexity of exported goods.

This article was, of course, inspired by the work of Hausmann, Hwang and Rodrik (2007). The authors analysed the same feature of trade and the set of regressors in this article is based on the one suggested in their seminal paper, however also developing their original framework both in terms of the methods used and the conceptual approach.

First of all, the authors included the time dimension of the analysed phenomenon, while they reduced that dimension by averaging all the variables. Moreover, the study used both static and dynamic panel methods to fully exploit the impact of the temporal variability of the data. Secondly, the chosen approach - the use of the Anemiya-MaCurdy estimator - enables tackling the issue of endogeneity - not addressed by Hausmann, Hwang and Rodrik (2007).

Another crucial difference is that Hausmann, Hwang and Rodrik (2007) employed another complexity measure as the dependent variable - they used EXPY, while this study focused on the Economic Complexity Index (ECI). The authors believe that ECI is a better measure because of its wider availability and its construction, which makes it more independent from the GDP per capita time series.

To the best of the authors' knowledge, this article is also the first one that systematically studies the impact of economic integration - namely EU accession - on export complexity. Gabrielczak and Serwach (2017) assessed how the adoption of the euro affected that feature in Slovenian trade. This article differs from their study in at least two ways. Firstly, they focused on deep integration, since they concentrated on the European Monetary Union, whilst this studyonly looked at the European Union, because it is more oriented towards the removal of the existing barriers to trade and production factors flows. Monetary integration is more connected with the coordination of macroeconomic policies with the ultimate aim of establishing a common monetary policy. Secondly, Gabrielczak and Serwach (2017) applied the Synthetic Control Method (SCM) for the case of Slovenia. This method is a proper tool to build a counterfactual scenario - e.g. that a given member of the Eurozone could be outside of that bloc. However, that method is applied whenever comparative case studies are conducted and the methods of generalization of the results are still in their infancy (see, for example, $\mathrm{Xu}$ 2017). This article applied panel data estimation methods in order to obtain results that apply to many different countries. 
The aim was to assess if EU membership has any impact on export complexity. The article is organized as follows. Section 2 defines export complexity and stresses its importance. Section 3 describes the empirical study - the ideas behind it, the hypotheses, the data and the results. Section 4 discusses the results, while Section 5 concludes.

\section{EXPORT COMPLEXITY - DEFINITION, IMPORTANCE, DETERMINANTS}

Export complexity has become a heavily analysed feature of international trade. Not only does it influence the patterns of trade among nations, but it may be also an important determinant of economic growth. The idea that the sophistication of goods in exports may be a source of growth has been popularized by economists since the publication of the seminal paper by Hausmann, Hwang and Rodrik (2007).

The literature offers two common definitions of complexity. The first one describes complexity as the level of technical advancement of exported goods (Lall 2000). The second one presents complexity as the range of inputs required for the production process (Hausmann, Hwang and Rodrik 2007). These two seemingly unrelated approaches are in fact correlated, as in practice more advanced technologies require longer production processes with higher specialisation and a greater variety of inputs. In such case both definitions can be treated as equivalent to a large extent.

Economic complexity is considered very important for economic development and stability because of the two roles it plays in the economy. Firstly, complexity stimulates the pace of economic growth. From one point of view, complex goods are more difficult to produce, therefore they include higher profit margins, resulting in generally higher profitability of exports. However, more complex goods require more human capital, thus they promote investment in it and stimulate efficiency growth, which leads to higher economic dynamics (Hausmann, Hwang and Rodrik 2007). This stimulating effect is especially visible in economies with liberalised trade and without overvalued currencies (Anand, Mishra and Spatafora 2012). Since the shift from complexity to economic growth is based on rather long investment processes, the impact is visible in long-run analyses, while in the short term it remains negligible (Stojkoski and Kocarev 2017). Furthermore, economic complexity affects the pace of economic growth since it determines the country's stable state to which the economy is heading.

Secondly, Koren and Tenreyro (2013) claim that economic complexity also fosters shock absorption. Complex goods require more components as inputs. 
Some of those components are specific (unique), but the majority of them are standardised and can be relatively easily substituted. The replacement of supplies is associated with transaction costs, mostly connected with the need for finding a new source of supply and the necessary negotiations. However, a country with a wider range of suppliers also has a greater network of contacts, which reduces the transaction cost of a single substitution. In this case higher complexity reduces susceptibility to supply-side shocks.

The significance of the economic complexity for growth and volatility leads naturally to the question about its determinants. Hidalgo and Hausmann (2009) claimed that economic complexity depends on the skills available within the economy. Moreover, there is a common core of skills that enables the production of complex goods. New skills are developed gradually and new comparative advantages tend to appear near the previously revealed ones (Hidalgo, Klinger, Barabási and Hausmann 2007)1.

Hausmann, Hwang and Rodrik (2007) offered a basic set of complexity determinants, identifying four such factors. The first one is the level of real GDP per capita. The rationale is that income represents the existing level of development in most of its aspects, including technological advancement. Thus, in this case GDP per capita approximates the current level of technology and is believed to be positively correlated with economic complexity. These ideas are supported by the findings of Anand, Mishra and Spatafora (2012), who stressed the importance of technological development and a proper R\&D support policy for the stimulation of economic complexity.

The second important aspect is found in the labour market. Hausmann, Hwang and Rodrik (2007) emphasized the importance of access to both a cheap and skilled labour force. The low price of labour reduces the risk of innovative enterprises, diminishing barriers for obtaining new competences. They approximated it through the size of population, which should be positively correlated with economic complexity. The level of skilfulness is evaluated using the human capital index, which is also expected to positively influence complexity. Anand, Mishra and Spatafora (2012) supported this view and stated that educational policies can significantly impact economic complexity.

1 This path dependency is often described as the problem of monkeys and trees (Lederman and Maloney 2012). The companies (monkeys) can only move to a sector or branch with similar requirements (neighbouring tree), therefore new skills (and new products) that the economy offers are close to the initially disclosed set. Moreover, if the set of available skills is bigger (the forest is dense), it is easier to develop new products with new combinations of skills required (swing among the trees). Thus, more competences at the beginning of the process allow for the quicker attainment of further skills. 
The third determinant of economic complexity is institutional quality, which Hausmann, Hwang and Rodrik (2007) measured with the Rule of Law index. Even though their original results eventually suggest that this variable is statistically insignificant, when controlling for the level of GDP per capita, Costinot (2009) raised the argument, that a sound institutional environment stimulates cooperation among agents that enables the production of more complex goods.

The last factor that may influence economic complexity is the country's size. That determinant, reflected by the geographic area, was included by Hausmann, Hwang and Rodrik (2007) in their list of regressors. One may justify such an inclusion by the importance of natural resources. For instance, Lederman and Maloney (2012) provided the insight that, despite all of the existing controversies, an abundance of natural resources is generally beneficial for economic growth, technological advancement and economic complexity. However, it may create a basket of export goods that could be dominated by non-processed products, lowering the aggregate export complexity.

To summarize, economic complexity in general is determined by sufficient technological advancement, accessibility of a relatively cheap and skilled labour force, as well as a supportive institutional environment. However, Hausmann, Hwang and Rodrik (2007) themselves admit that their model is not fully complete, as there are many deviations from its estimations observed, especially among low-income countries. This proves that there is still a need to develop a set of complexity determinants.

\section{RESEARCH FRAMEWORK}

The European Union is a unique phenomenon and an unprecedented example of deep regional integration, well-known for having a huge impact on flows of trade and production factors. The authors' aim was to determine whether this also applies to the problem of economic complexity. The existing literature provides examples of the possible effects of integration on complexity, but the suggested mechanisms lead to opposite conclusions and require further studies.

In most approaches, integration should lead to an increase of economic complexity and is associated with a reduction of barriers to the movement of production factors. First of all, integration causes an increase of capital flows, especially the higher inflow of foreign direct investment (FDI) (Antras and Foley 2011). FDI inflows trigger an increase in the quality and greater sophistication of exports (Xu and Lu 2006; Harding and Javorcik 2012; Eck 
and Hubert 2016). Foreign companies may have higher productivity or greater financial resources, in which case they supply goods of higher complexity to the host economy ${ }^{2}$. FDI inflows may also lead to increased competition and the potential diffusion of any new know-how. Therefore the very presence of foreign affiliates causes an increase of economic complexity in the host country (Javorcik, Lo Turco and Maggioni 2018). FDI is the most important channel through which integration stimulates complexity, because it allows for the movement of both capital and labour force, especially the skilled workers. Another possibility is the further international fragmentation of production processes within the network of independent enterprises. In both cases, competences previously unavailable in a given economy can now be transferred into it (Hidalgo and Hausmann 2009). Such solutions, in fact both FDI and outsourcing, are typical for modern corporations (Costinot, Oldensky and Rauch 2009).

However, some researchers suggest a different vision. Trade liberalisation strengthens specialisation, which in the case of less developed partners such as new EU member states, means focusing on less advanced and less complex goods (Young 1991). Empirical research on developing countries only shows that trade liberalisation in their case leads to a decrease of investment in human capital (Galor and Mountford 2008), which corresponds with a decline in economic complexity or at least hampering the potentially existing growing trends. If this is the case, the integration has an ambivalent effect, which increases the polarisation between less developed partners, producing less complex goods, and more developed partners, engaging in more and more complex production.

\subsection{Data and methodology}

The dependent variable in this research is export complexity measured by the economic complexity index (ECI), available on the Atlas of Economic Complexity (AEC) website. Hausmann, Hwang and Rodrik (2007) in their original research used a different measure, called EXPY, calculated on the basis of GDP per capita, which is used as a measure of productivity of countries that produce certain goods. This creates the technical problem of a very strong correlation between EXPY and GDP per capita, whereas ECI is based on the revealed comparative advantages which are divided into two dimensions. One

\footnotetext{
2 The modern theory of international trade proves that companies engaging in foreign direct investment are in fact the most productive ones, no matter what type of investment is analysed - horizontal FDI (Helpman, Melitz and Yeaple 2004) or vertical FDI (Antras and Helpman 2004).
} 
is diversity, which shows how many distinctive products an economy produces, and the other ubiquity, which shows how popular the production of a certain good is in other countries of the world. Hence ECI is based on the competences required to produce certain goods, which means that it is in fact a closer approximation of the theoretical concept behind the idea of economic complexity. Moreover, AEC provides a database of 124 countries in a sample period of over two decades, which is not comparable in the case of EXPY. Those two arguments elevated ECI to the position of a new standard of the complexity measure commonly used in contemporary literature. Hausmann, Hwang and Rodrik (2007) provided an extensive technical description of EXPY, while a thorough presentation of ECI and more detailed discussion of the differences between the two measures of complexity was provided by Valette (2016).

The authors' choice of regressors was also based on the seminal paper by Hausmann, Hwang, and Rodrik (2007), also using population, real GDP per capita and the human capital index (obtained from the Penn World Table 9.1 (Feenstra, Inklaar, and Timmer 2015)), countries' area (from the CEPII GeoDist Database (Mayer and Zignago 2011)) and the Rule of Law index (from the World Bank's Worldwide Governance Indicators database). Apart from those variables, the study also employed a dummy for EU membership.

As a time-invariant endogenous variable the authors introduced the type of legal system as one of the regressors, with data from the CIA World Factbook. It is constructed as a dummy variable which takes 1 if the country adopted common law. Three countries (Israel, South Korea and Norway) were described by the CIA World Factbook as having mixed systems. For the sake of simplicity, they were classified as having common law legal systems. However, their reclassification (as if they had civil law systems) did not qualitatively alter the results.

In the study data for 1995-2014 were used due to the availability of the ECI. The panel comprised 36 countries: Australia, Austria, Belgium, Bulgaria, Canada, Chile, the Czech Republic, Denmark, Estonia, Finland, France, Germany, Greece, Hungary, Ireland, Israel, Italy, Japan, Latvia, Lithuania, Mexico, the Netherlands, Norway, New Zealand, Poland, Portugal, Republic of Korea, Romania, Slovakia, Slovenia, Spain, Sweden, Switzerland, Turkey, the United Kingdom, and the United States.

The study used the Amemiya-MaCurdy estimator, which is designed to solve the problem of endogenous variables included in the estimated function (see Baltagi, 2008). It is based on the estimation of the parameters of the following function: 


$$
y_{i t}=\boldsymbol{X}_{1 i t} \beta_{1}+\boldsymbol{X}_{2 i t} \beta_{2}+\boldsymbol{Z}_{1 i t} \delta_{1}+\boldsymbol{Z}_{2 i t} \delta_{2}+\mu_{i}+\epsilon_{i t}
$$

where $\boldsymbol{X}_{1 i t}$ is a $1 \times k_{1}$ vector of observations on exogenous, time-varying variables that are assumed to be uncorrelated with $\mu_{i}$ and $\epsilon_{i t} ; \boldsymbol{X}_{2 i t}$ is a $1 \times k_{2}$ vector of observations on endogenous, time-varying variables that are assumed to be correlated (or possibly correlated) with $\mu_{i}$ and orthogonal to $\epsilon_{i t} ; \boldsymbol{Z}_{1 i t}$ is a $1 \times g_{1}$ vector of observations on exogenous, time-invariant variables that are assumed to be uncorrelated with $\mu_{i}$ and $\epsilon_{i t} ; \boldsymbol{Z}_{2 i t}$ is a $1 \times g_{2}$ vector of observations on endogenous, time-invariant variables that are assumed to be correlated (or possibly correlated) with $\mu_{i}$ and orthogonal to $\epsilon_{i t} ; \mu_{i}$ is the panel-level random effect that is unobserved by an econometrician and assumed to have zero mean and finite variance and to be independently and identically distributed over the units observed (countries); $\epsilon_{i t}$ is the idiosyncratic error with zero mean and finite variance and i.i.d. over all the observations in the data; $\beta_{1}, \beta_{2}$, $\delta_{1}, \delta_{2}$ are $k_{1} \times 1, k_{2} \times 1, g_{1} \times 1$, and $g_{2} \times 1$ coefficient vectors, respectively; units are given by $i=1, \ldots . n$, where $n$ is the number of units (countries) in the sample and time dimension is given by $t=1, \ldots, T_{i}$.

The authors classified the regressors into the above mentioned categories: $\boldsymbol{X}_{1 i t}$ is composed of population (natural logarithm), $\boldsymbol{X}_{2 i t}$ includes real GDP per capita, human capital index (both in natural logarithms), rule of law index, EU dummy (together with its interactions with GDP per capita), $\boldsymbol{Z}_{1 i t}$ is area (natural logarithm), and $\boldsymbol{Z}_{2 i t}$ is the common law dummy variable.

\subsection{Hypotheses}

The main hypothesis tested in this study was that European integration had an impact on export complexity. The authors could not, however, determine the sign of the relation a priori, since it is possible that integration both lowers and increases such a complexity.

Hausmann, Hwang and Rodrik (2007) suggested a set of hypotheses about export complexity determinants, which this study referred to. As for population, they modelled export complexity as depending positively on the size of the country. However, their analysis was supply-sided, hence they did not take into account the fact that bigger markets may have lower export complexity, since sophisticated goods are sold domestically instead of being traded abroad. Therefore, the authors set the null hypothesis as the lack of impact of population on export complexity, while the alternative one was that population has an influence on that complexity (without determining the exact sign). Another 
measure of country size - area - was also tested with a two-sided alternative hypothesis. Hausmann, Hwang and Rodrik (2007) claimed that this variable may positively affect export sophistication. However, since a bigger area may lead to more resource discoveries, it may also drive the export basket towards one dominated by natural resources and non-processed products.

The authors also set the hypothesis for human capital in a relatively similar way. On the one hand, Hausmann, Hwang and Rodrik (2007) emphasized the positive role of human capital in the production of sophisticated goods, since countries with a higher stock of human capital may specialize in complex products. On the other hand, Costinot (2009) convincingly demonstrated that more human capital corresponds with fewer parties cooperating in the production process, so human capital lowers complexity whenever it is defined as the number of agents involved in the production. This inconclusiveness of theoretical literature led to the two-sided alternative hypothesis.

The last determinant of complexity taken from Hausmann, Hwang and Rodrik (2007) - GDP per capita - seems to affect that feature of trade positively. The higher the income per person, the more resources may be devoted to the production of complex goods. Since that process requires better machines and equipment, it is reasonable to expect that richer countries specialize in sophisticated products.

The only variable introduced to this analysis, which was not utilized by Hausmann, Hwang and Rodrik (2007), is a type of a legal system. The study did not form any specific expectations about the sign of the estimated parameter. That variable was used mainly for technical reasons as the methods applied required at least one time-invariant endogenous variable.

\section{RESEARCH FINDINGS}

\subsection{Results}

The results support the claim that European integration has led to increased export complexity in member countries. The results indicate that the EU members' ECI value on average was higher by roughly 0.08 than that of nonmember states. The coefficient was not only positive, as expected, but also statistically significant. Surprisingly, several variables that intuitively should have had an important bearing on export complexity turned out to be insignificant, e.g. the human capital index and the rule of law index. It seems that all that mattered for the ECI was EU status and real GDP per capita. Table 1 summarizes the baseline estimation. 
Table 1

Baseline estimation - Amemiya-MaCurdy

\begin{tabular}{l|c|c|c|c}
\hline \multicolumn{1}{c|}{ Independent variable } & Coefficient & Standard error & $z$ & $p>|z|$ \\
\hline Constant & -3.182 & 8.154 & -0.39 & 0.696 \\
\hline \multicolumn{5}{c}{ time-varying exogenous variables } \\
\hline Population (ln) & -0.600 & 0.110 & -5.43 & 0.000 \\
\hline \multicolumn{5}{c}{ time-varying endogenous variables } \\
\hline Real GDP per capita (ln) & 0.187 & 0.061 & 3.08 & 0.002 \\
\hline Human capital (ln) & -0.220 & 0.178 & -1.24 & 0.217 \\
\hline Rule of law & 0.043 & 0.044 & 0.98 & 0.328 \\
\hline European Union & 0.079 & 0.031 & 2.57 & 0.010 \\
\hline \multicolumn{5}{c}{ time-invariant exogenous variables } \\
\hline Area (ln) & 0.365 & 0.706 & 0.52 & 0.606 \\
\hline \multicolumn{5}{c}{ time-invariant endogenous variables } \\
\hline Common law & -1.224 & 4.062 & -0.30 & 0.696 \\
\hline
\end{tabular}

Source: own calculation.

Table 2

Estimation with the interaction term - Amemiya-MaCurdy

\begin{tabular}{l|c|c|c|c}
\hline \multicolumn{1}{c|}{ Independent variable } & Coefficient & Standard error & $z$ & $p>|z|$ \\
\hline Constant & -3.611 & 7.821 & -0.46 & 0.644 \\
\hline \multicolumn{5}{c}{ time-varying exogenous variables } \\
\hline Population (ln) & -0.557 & 0.110 & -5.08 & 0.000 \\
\hline \multicolumn{5}{c}{ time-varying endogenous variables } \\
\hline Real GDP per capita (ln) & 0.276 & 0.064 & 4.33 & 0.000 \\
\hline Human capital (ln) & -0.251 & 0.176 & -1.43 & 0.154 \\
\hline Rule of law & 0.033 & 0.043 & 0.77 & 0.442 \\
\hline European Union & 2.670 & 0.625 & 4.27 & 0.010 \\
\hline Interaction term & -0.263 & 0.063 & -4.15 & 0.000 \\
\hline \multicolumn{5}{c}{ time-invariant exogenous variables } \\
\hline Area (ln) & 0.324 & 0.677 & 0.48 & 0.633 \\
\hline \multicolumn{5}{c}{ time-invariant endogenous variables } \\
\hline Common law & -1.206 & 3.895 & -0.31 & 0.757 \\
\hline
\end{tabular}

Source: own calculation. 
The authors checked for any heterogeneity in those results. The strategy was based on the intuitive reasoning that at some levels of economic development, the positive influence may disappear - countries may follow different specialization patterns according to their comparative advantages (when one country specializes in more complex goods, the other may specialize in less sophisticated products). The study tried to check that possibility by introducing the interaction between the country's EU status and its real GDP per capita in these estimations, using the product's EU status and the natural logarithm of GDP per capita.

It became clear that EU status was once again significant. Its impact on ECI was now dependent not only on the coefficient of the EU dummy but also on the coefficient of the interaction term. Both were significant and had opposite signs, which means that EU members benefited from European integration (in terms of their ECI levels) only if their GDP per capita was lower than 25,444 USD.

\subsection{Discussion}

As a starting point one should stress that, according to the existing literature, more complex exports allow for higher profitability, more shock resistance and better competitiveness. Therefore it stimulates economic development and increasing complexity, measured by ECI, is a desired process. The results presented in the previous section suggest that, when considering the typical determinants of economic complexity, the levels of ECI in OECD countries were mostly based on the population or a GDP per capita of the country.

GDP per capita approximates the current level of technological development, which may be treated as a set of skills available in the economy. Each product, on the other hand, represents an embodiment of a combination of skills. If the available set is larger, then there are also more potentially profitable combinations, which could at the same time include more distinct skills. This literally means higher complexity.

Population, as stated in Section 3.2, had no precisely defined expected sign of the estimated coefficient. Since the study obtained a negative sign, it means that the demand-side explanation was more powerful than the supply-side one. In other words, generally it was the size of the market that influenced the results: bigger markets may diminish export complexity due to the fact that sophisticated goods are sold domestically instead of being traded abroad.

One may wonder why other factors with strong theoretical justification turned out to be insignificant. To start with, in the modern integrated global economy it is relatively easy to import resources, which may make domestic 
availability (represented by area) less important. As for human capital and quality of institutional environment, their insignificance may be a result of the selected sample. The studied OECD members are considered to be relatively well-developed compared to the rest of the world, which means that probably all of them have effective institutional systems and reasonable levels of human capital, or at least these factors do not differentiate the sample of countries strongly enough.

The novelty of this research is based on including EU accession and testing its impact on ECI. When simply considering EU membership as a dummy in the regression, the results suggest that this impact is generally positive. When allowing for a more intricate relation, the results suggest that EU membership provides stimulation of economic complexity for countries with real GDP per capita below the threshold of 25,444 USD, which is probably a result of an inflow of FDI, leading to a rise of productivity. From that point of view one can form two interesting policy recommendations associated with integration among countries at different levels of development.

First of all, the results indicate that integration stimulates the growth of complexity for the less developed partners. From this point of view the fear that a less developed country will only play the role of a cheap labour force provider, and integration with richer partners will hamper its development, seems to be invalid. Secondly, however, the more developed countries (definitely those with GDP per capita exceeding 25,444 USD) should not rely on integration alone to promote a structural change of their exports. In their case integration may in fact cause a shift in comparative advantages, effectively lowering their ECI levels.

The study's results are in line with those of Gabrielczak and Serwach (2019), who used the synthetic control method to analyse the case of Slovakia and its possible ECI levels should it not access the EU. Their analysis based on building counterfactual scenarios, proved that had Slovakia not integrated with the EU, its export complexity would have largely decreased after 2004, while in reality it grew. Slovakia's real GDP per capita at the time of accession was below 17,000 USD (taking 2011 as the reference year), therefore Slovakia, like all the countries of the 2004 enlargement, was a relatively less developed partner for the old member states.

\section{CONCLUSION}

Export complexity has been analysed by many researchers, however without a thorough discussion about its determinants. The authors filled this gap by studying the impact of economic integration on that aspect of 
international trade, and applied the Amemiya-MaCurdy estimator to overcome the problem of endogeneity. Moreover, the study checked the possibility that European integration has had a heterogeneous impact on countries' economic complexity depending on their level of development. According to the results obtained, EU membership has on average led to increased export sophistication, measured by ECI. Such a positive effect was especially evident for relatively poorer member states, since only countries below a certain income threshold gained from integration in the form of higher export complexity. This threshold was estimated at around 25,444 USD per capita. The article fills an important research gap, but at the same time more studies about the forces behind export complexity are needed. One of the possible further developments of this study is to identify the exact mechanisms that link integration with complexity. The emergence of new comparative advantages, the engagement in the production chains, and the impact of FDI are all possible outcomes.

\section{REFERENCES}

Anand, R., Mishra, S., Spatafora, N., Structural Transformation and the Sophistication of Production, "International Monetary Fund Working Paper" 12/59. Washington, DC, 2012.

Antras, P., Foley, F. C., Regional Trade Integration and Multinational Firm Strategies [in:] Barro, R., Lee, J. W. (eds.), Costs and Benefits of Economic Integration in Asia, pp. 208240. Oxford University Press, Oxford 2011.

Baltagi, B., Econometric Analysis of Panel Data. Wiley, Chichester 2008.

Costinot, A., On the origins of comparative advantage, "Journal of International Economics", No. 77, pp. 255-264, 2009.

Costinot, A., Oldensky, L., Rauch, J. E., Adaptation and the Boundary of Multinational Firms, "NBER Working Paper", No. 14668, Cambridge, MA, 2009.

Eck, K., Huber, S., Product sophistication and spillovers from foreign direct investment, "Canadian Journal of Economics", No. 49(4), pp. 1658-1684, 2016.

Erkan, B., Yildirimci, E., Economic Complexity and Export Competitiveness: The Case of Turkey, "Procedia - Social and Behavioral Sciences", No. 195, pp. 524-533, 2015.

Gabrielczak, P., Serwach, T., The impact of the euro adoption on the complexity of goods in Slovenian exports, "Proceedings of Rijeka Faculty of Economics: Journal of Economics and Business", No. 35(1), pp. 45-71, 2017.

Galor, O., Mountford, A., Trading Population for Productivity: Theory and Evidence, "Review of Economic Studies", No. 75(4), pp. 1143-1179, 2008.

Harding, T., Javorcik, B., Foreign Direct Investment and Export Upgrading, "Review of Economics and Statistics", 94(4), pp. 964-980, 2012.

Hausmann, R., Hwang, J., Rodrik, D., What you export matters, “Journal of Economic Growth”, No.12(1), pp. 1-25, 2007. 
Hidalgo, C. A., Hausmann, R., The building blocks of economic complexity, "Proceedings of the National Academy of Sciences", No. 106(26), pp. 10570-10575, 2009.

Hidalgo, C. A., Hausmann, R., The network structure of economic output, "Journal of Economic Growth", No. 16(4), pp. 309-342, 2011.

Hidalgo, C. A., Klinger, B., Barabási, A. L., Hausmann R., The Product Space Conditions the Development of Nations, "Science", No. 317(5837), pp. 482-488, 2007.

Javorcik, B. S., Lo Turco, A., Maggioni D., New and Improved: Does FDI Boost Production Complexity in Host Countries?, "The Economic Journal", No. 128(614), pp. 2507-2537, 2018.

Koren, M., Tenreyro, S., Technological Diversification, "The American Economic Review", No. 103(1), pp. 378-414, 2013.

Lall, S., The Technological Structure and Performance of Developing Country Manufactured Exports, 1985-1998, QEH Working Papers 44, Queen Elizabeth House, University of Oxford, 2000.

Lederman, D., Maloney, W. F., Does What You Export Matter? In Search of Empirical Guidance for Industrial Policies. The World Bank Group, Washington, DC, 2012.

Stojkoski, V., Kocarev, L., The Relationship Between Growth and Economic Complexity: Evidence from South-East and Central Europe, "MPRA Paper”, No. 87432, Munich, 2017.

Valette, J., Do migrants transfer productive knowledge back to their origin countries?, "CERDI Études et Documents", No. 22, Clermont Ferrand, 2016.

$\mathrm{Xu}$, Y., Generalized Synthetic Control Method: Causal Inference with Interactive Fixed Effects Models, "Political Analysis", No. 25(1), pp. 57-76, 2017.

$\mathrm{Xu}, \mathrm{B} ., \mathrm{Lu}, \mathrm{J} .$, The impact of foreign firms on the sophistication of Chinese exports, "China Economic Review", No. 20(3), pp. 425-439, 2006.

Young, A., Learning by Doing and the Dynamic Effects of International Trade, "Quarterly Journal of Economics", No. 106(2), pp. 369-405, 1991.

Received: January 2019, revised: February 2020 